Article

\title{
Crowdsourcing for Sustainable Urban Logistics: Exploring the Factors Influencing Crowd Workers' Participative Behavior
}

\author{
Lijuan Huang ${ }^{1}$, Guojie Xie ${ }^{1, *}$, John Blenkinsopp ${ }^{2}$, Raoyi Huang ${ }^{3}$ and Hou Bin ${ }^{4}$ \\ School of Management, Guangzhou University, Guangzhou 510000, China; somhuanglj@gzhu.edu.cn \\ 2 Newcastle Business School, Northumbria University, Newcastle upon Tyne NE1 8ST, UK; \\ jblenk68@gmail.com \\ 3 Faculty of Engineering, The Hong Kong Polytechnic University, Hong Kong 37075, China; \\ 18082421d@connect.polyu.hk \\ 4 School of Business, Hunan University of Technology, Zhuzhou 412000, China; bhv168@hnu.edu.cn \\ * Correspondence: 1111965003@e.gzhu.edu.cn; Tel.: +137-9437-5559
}

Received: 15 March 2020; Accepted: 9 April 2020; Published: 12 April 2020

check for updates

\begin{abstract}
With crowd logistics becoming a crucial part of the last-mile delivery challenge in many cities, continued participation of crowd workers has become an essential issue affecting the growth of the crowd logistics platform. Understanding how people are motivated to continue their participation in crowd logistics can provide some clarity as to what policies and measures should be undertaken by the industry to support its further growth. Using the Push-Pull-Mooring (PPM) theory, we developed a research model to explain the factors influencing crowd workers' participative behavior. Survey data from 455 crowd workers were analyzed using SmartPLS3.0 software. The results show monetary rewards and trust have a significant positive impact on the willingness of crowd workers to continue participating in crowd logistics, while work enjoyment from previous work and entry barriers for work have a significant negative impact. Trust plays an intermediary role between monetary incentives and crowd workers' willingness to continue participating. Based on the findings of this study, we recommend that crowd logistics platforms should offer reasonable monetary incentives and keep these under constant review, build a high degree of trust and cooperation with their crowd workers, and initiate activities geared towards promoting satisfaction at work.
\end{abstract}

Keywords: crowd workers; crowd logistics; PPM theory; motivating factors

\section{Introduction}

The organization and execution mode of urban logistics have changed dramatically with the continued development of the sharing economy $[1,2]$ and progress in information and communication technology [3]. Crowd logistics have emerged as a new logistics organization mode, and become widely adopted in urban logistics [4]. More and more logistics enterprises are outsourcing packages to a growing number of people via online platforms $[5,6]$. Crowd logistics has gradually become an essential solution to the last-mile delivery challenges in cities $[7,8]$, growing rapidly around the world. Sweden's MyWays [9], Flexe and TaskRabbit in the USA [9], and China's JD-dada, 51 Delivery, FlashEx, and Renren Express [10] are some of the most prominent crowd logistics companies, with huge customer and participant bases. For example, as of 2019, the crowdsourcing business of Renren Express covered 92 cities, serving nearly two million merchants, and having more than ten million individual users in China [11]. In terms of sustainability within logistics more generally, Purhejazy et al. [12] used data envelopment analysis to compare different configurations within supply chain management and 
their relative resilience. The present study contributes to improving our understanding of one aspect of this system, the use of crowdsourcing to tackle the last-mile delivery challenge.

In crowd logistics, the delivery task is outsourced by the employer to an indefinite group of individuals through the online platform, who then use their underutilized vehicles to make timely deliveries to customers' locations [7]. Based on the concept of sharing, crowd logistics plays a vital role in enhancing the sustainability of urban logistics $[3,13,14]$ and has become a major focus for research on tackling the problem of last-mile delivery in cities [13]. By using crowdsourcing, the emissions of pollutants, such as nitrogen oxides, PM2.5, and PM10 from cargo trucks, can be reduced by about 55\% [13]. Research has also shown that crowd logistics can reduce the pressure on the urban transportation system, improve the distribution efficiency of urban logistics, and cut down carbon emissions [9,14-16]. In addition, Melo and Macharis have proposed that crowd logistics could provide benefits for all stakeholders in the last-mile delivery process (e.g., better services for customers, additional revenue for crowdsourcing operators, and profits for platform providers) [15]. Crowd workers can also get monetary rewards and experience enjoyment of work in the process of participation $[9,17,18]$.

However, even with the numerous advantages of crowd logistics, many operational problems still exist $[3,19]$. One of the significant challenges is how to get more people to participate in crowd logistics and maintain the motivation to participate among crowd workers [18,20,21]. Key reasons that seem likely to decrease the willingness of crowd workers to participate in crowd logistics include: (1) crowd logistics is still in the exploration stage, facing a number of management, technical and legal challenges [19]; (2) monetary reward alone may not be enough to motivate continued participation of crowd workers [22]; (3) the time, energy and equipment costs incurred by the crowd workers may discourage continued participation [9,23]; and (4) risks and safety issues caused by delays in delivery, loss or damage to goods, and traffic accidents may reduce trust between the crowd workers and employer (or platform) $[3,18,24]$. Resolving the problems that may depress participation in crowdsourcing has become a critical issue in the field of logistics research.

Most of the current studies on this issue have focused mainly on concepts (e.g., Mladenow et al., 2015 [3]; Mladenow et al., 2016 [9]; Carbone et al., 2017 [24]) and on the simulation stage (e.g., Chen and Chankov, 2017 [7]; Arslan et al., 2019 [25]), and lack empirical analysis from the perspective of crowd workers [14,18], crowdsourcing communities [26], and leader support [27]. To address this knowledge gap, we reviewed the literature to construct a Push-Pull-Mooring (PPM) theoretical model of the factors affecting the willingness and continued participation of crowd logistics workers. This study contributes to the crowd logistics literature by examining the motivations affecting the continued participation among crowd workers. We modeled and tested the influences of the push, pull, and mooring factors and explored the mediating role of trust in the process, contributing to the application of PPM theory to a wider range of phenomena. Our study provides insights into how crowd logistics platforms might best attract, motivate and retain crowd workers.

The rest of this paper is arranged as follows: the second section presents the literature review; the third section analyzes the theoretical background, constructs the theoretical model, and puts forward the research hypothesis; the fourth section presents the research method and empirical results; the fifth section discusses the theoretical implications and practical implications of the study, and proposes some recommendations; and, finally, the sixth section presents the conclusion.

\section{Literature Review}

\subsection{The Concept of Crowd Logistics}

Crowd logistics is an important and rapidly growing form of crowdsourcing [3]. The term "crowdsourcing" was first coined by Howe in 2006 [5], and he subsequently defined it as taking a task traditionally done by selected agents, such as an employee or contractor, and outsourcing the task to an unknown but significant number of people through open recruitment [28]. Crowdsourcing 
empowers the masses to complete tasks once exclusively accomplished by a few professionals [28]. The growing use of crowdsourcing has attracted the attention of researchers, who have offered their own definitions (e.g., Estelles-Arolas and Gonzalez-Ladron-De-Guevara, 2012 [29]; Doan et al., 2011 [30]; Hosseini et al., 2014 [31]). In contrast to Howe's initial definition, the emphasis on scholarly definitions has shifted towards the participatory online behavior and the belief that implementation of crowdsourcing tasks requires the provision of mutual benefits for the crowd worker and the platform [29-31]. Together with continued advancements in communication technology (e.g., the extensive application of social software and Global Positioning System (GPS)), sub-disciplines such as crowdfunding, crowd search, and crowd logistics have emerged [3,9].

Crowd logistics, also referred to as crowd transportation, crowd delivery, or collaborative logistics [14], builds upon sharing economic concepts [2] to effectively combine logistics with crowdsourcing [24]. The delivery task is outsourced by the employer to an indefinite group of individuals through the online platform, who then use their underutilized assets (such as bicycles, electric bicycles, and cars) to make timely deliveries to customers' locations [7]. Crowd logistics can include "tournament-based crowdsourcing" (where there is only one winner) or "collaboration-based crowdsourcing" (where collaboration among crowd workers occurs to solve the problem) [23]; both forms are present for crowd logistics in an urban setting. On the one hand, the crowd worker needs to select the order that delivers the goods within the specified time according to its own delivery ability and speed (the crowd worker needs to compete with time and himself). On the other hand, crowd workers need to work together to be able to deliver the orders on the crowdsourcing platform (crowd workers cooperate to finish all the delivery orders within a certain period of time). In the process, crowd workers also receive monetary and non-monetary rewards [25,32].

\subsection{Motivations for Crowd Workers' Continued Participation}

A number of scholars have analyzed the motivation behind crowd workers' continued participation in crowd logistics through cases, questionnaires, and conceptual discussions. For example, Rai et al. [14] and Horton and Chilton [32] found crowd workers are motivated to participate in crowdsourcing by both monetary (e.g., salary or money, gift card, and performance bonus) and non-monetary rewards (e.g., psychological satisfaction). Mladenow et al. [3] propose the motivation of crowd workers arises from a considerable number of psychological factors, which could either be intrinsic or extrinsic in nature. Intrinsic motivation value includes the desire to experience new things, the sharing of knowledge with others, and the enjoyment of doing the task itself; extrinsic value includes the realization of common goals, the recognition of others, the need for satisfying self-expression and uniqueness $[3,17,33]$.

On the other hand, several factors can deter people from participating. For instance, Mladenow et al. [3] found the existence of potential risks, such as extra costs, the absence of relevant laws, delivery delay, and unclear distribution of responsibilities inhibit crowd workers' continued involvement. Similarly, De Groen and Maselli [34] suggest crowd workers can get discouraged by problems such as financial instability, lack of social protection, isolation, and pressure, blurred boundaries between work and private life, fierce competition, and uncertainty caused by short-term schedules. Rougès and Montreuil [35] found trust between the crowd worker and the platform can significantly motivate or deter crowd workers' continued participation (high trust between the platform and the crowd worker would encourage the continued participation of the crowd worker-otherwise, it would be detrimental to their continued participation). The motivating and inhibiting factors affecting crowd workers' continued involvement in crowd logistics are summarized in Table 1. 
Table 1. Factors influencing crowd workers' continued participation in crowd logistics.

\begin{tabular}{ccc}
\hline Types & \multicolumn{1}{c}{ Motivations/Influence Factors } & Reference \\
\hline Motivating factors & $\begin{array}{c}\text { Monetary and non-monetary rewards } \\
\text { Intrinsic motivation values include the desire to experience } \\
\text { something new, to share knowledge with others, and the } \\
\text { enjoyment of the task itself; Extrinsic motivation values } \\
\text { include the realization of common goals, the recognition of } \\
\text { others, and satisfaction of the need for self-expression } \\
\text { and uniqueness }\end{array}$ & $\begin{array}{c}\text { Chilton, 2010 [32] } \\
\text { Cladenow et al., 2015 [3]; Bayus, } \\
\text { 2013 [17]; Lusch et al., 1992 [33] }\end{array}$ \\
\hline \multirow{3}{*}{ Inhibiting factors } & $\begin{array}{c}\text { Extra charges, the absence of relevant laws, delivery delays } \\
\text { and unclear distribution of responsibility }\end{array}$ & Mladenow et al., 2015 [3] \\
\cline { 2 - 3 } & $\begin{array}{c}\text { Financial insecurities, lacking social protection, isolation, } \\
\text { and stress, blurring lines between the sphere of work and } \\
\text { private life, high competition and uncertainties due to } \\
\text { short-term schedules }\end{array}$ & De Groen and Maselli, 2016 [34] \\
\cline { 2 - 3 } & Level of trust between crowdsourcers and crowd workers & Rougès and Montreuil, 2014 [35] \\
\hline
\end{tabular}

\subsection{Theories for Crowd Workers' Continued Participation}

We reviewed the existing literature to identify the theories proposed to explain the motivations behind crowd workers' continued participation, in order to provide the theoretical basis for this study (see summary in Table 2). These theories include value-sensitive design theory, social exchange theory, agency theory, the theory of planned behavior, the post-acceptance model of information system (IS) continuance, and motivation theory. Drawing upon value-sensitive design theory, Deng et al. propose that access, autonomy, fairness, transparency, communication, security, responsibility, influence, and dignity affect crowd workers' continued participation [36]. Based on the social exchange theory, Ye and Kankanhalli [18] investigated 156 solvers and found that monetary rewards, skill improvement, work autonomy, enjoyment, and trust had positive effects on participation in crowdsourcing. Using agency theory, Chen and Chankov [7] argue that the reduction in average lap time required by each crowd worker could create a positive environment. This motivates crowd workers to constantly participate in crowdsourcing activities, which would be conducive to improving delivery efficiency [7]. Adopting the theory of planned behavior and the post-acceptance model of IS continuance, Liang et al. [37] found that participation motivation, subjective norms, and perceived behavior control have positive effects on participation, and that satisfaction plays an important mediating role in influencing and motivating crowd workers to continue their participation. Moreover, in terms of the motivation theory, Geri et al. found that reward consciousness, reputation, reciprocity, and reward value have a positive impact on sustaining participation among crowd workers [38].

Table 2. Theories used to explain crowd workers' participation in crowd logistics.

\begin{tabular}{ccc}
\hline Theories & Factors Affecting Participation & Reference \\
\hline Value-sensitive design theory & $\begin{array}{c}\text { Access, autonomy, fairness, transparency, } \\
\text { communication, security, accountability, } \\
\text { making an impact, and dignity }\end{array}$ & Deng et al., 2016 [36] \\
\hline Social exchange theory & $\begin{array}{c}\text { Monetary reward, skill enhancement, } \\
\text { work autonomy, enjoyment, and trust }\end{array}$ & Ye and Kankanhalli, 2017 [18] \\
\hline Agency theory & $\begin{array}{c}\text { The decrease of required average detour } \\
\text { time per crowd agent }\end{array}$ & Chen and Chankov, 2017 [7] \\
\hline $\begin{array}{c}\text { Theory of planned behavior, the } \\
\text { post-acceptance model of IS continuance }\end{array}$ & $\begin{array}{c}\text { Participation motivation, subject norm, } \\
\text { and perceived behavioral control } \\
\text { Motivation theory }\end{array}$ & $\begin{array}{c}\text { Awareness of rewards, prestige, } \\
\text { reciprocity and reward value }\end{array}$ \\
\hline
\end{tabular}

These studies provide a wealth of theoretical and practical value in analyzing and understanding the reasoning affecting crowd worker participation. However, existing studies have mostly focused on 
the factors that initially attract people to get involved in crowdsourcing activities and often overlook the factors that promote or discourage crowd workers' continued participation (see Liang et al. [37] for a notable exception). To address this research gap, we used the theory from migration studies to identify and analyze the factors influencing the continued participation of crowd workers.

\section{Theoretical Model and Hypothesis}

\subsection{PPM Theory}

The use of Push-Pull-Mooring (PPM) frameworks originates in the field of demography, where they have been used to model population migration [39-41] by capturing the influencing factors and motivations for people to move from one place to another over a period of time [40]. As shown in Figure 1, the theory mainly consists of three aspects [41]:

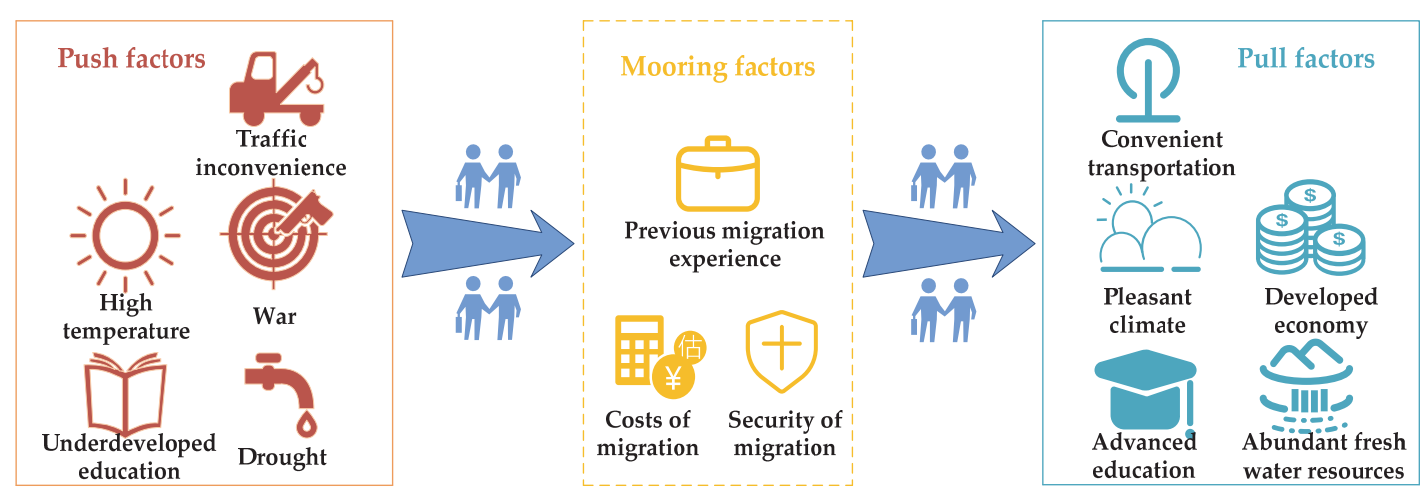

Figure 1. Schematic diagram of Push-Pull-Mooring (PPM) theory.

(1) Negative push factors from the origin, such as inconvenient transportation, drought, backward education, and war;

(2) Positive pull factors from the destination, such as pleasant climate, convenient transportation, developed economy, advanced education, and abundant freshwater resources; and,

(3) Constraints or facilitation factors from individuals and society, i.e., mooring factors, such as previous migration experience, migration cost, and migration security.

PPM theory has subsequently been applied in various disciplines. Tang et al. [42], for example, studied the factors influencing online shopping behavior from Personal Computer (PC) terminals to mobile intelligent devices using PPM Theory. Leng [43] used a PPM model to examine consumer switching behavior with regard to their mobile service providers. Jung et al. [39] tested the applicability of the theoretical model in traveler route selection and used it to analyze tourists' switching behavior. Bin et al. employed this theory in studying the influencing factors among enterprises implementing crowd logistics [44].

Furthermore, PPM theory explains the process of shifting from a poor environment to a better and more sustainable one. This is exactly in line with the problems encountered by current crowd logistics platforms. More specifically, crowd logistics platforms need to overcome the difficulty of motivating crowd workers to continue participating in crowd logistics. In this way, the sustainable operation of crowd logistics in the city can be better guaranteed.

Therefore, building on these previous studies and the relationship between theory and practice, we used the PPM theory as a framework for examining the factors affecting crowd workers' continued involvement in crowd logistics.

\subsection{Research Model Construction}

We applied PPM theory to group the factors influencing crowd workers' continued participation in crowd logistics into push, pull and mooring factors. The research model is shown in Figure 2. The model 
thus identifies six factors that are hypothesized to directly affect crowd workers' intention to continue participating in crowd logistics. In addition, we hypothesized, following Ye and Kankanhalli [18], that appropriate monetary rewards will enhance trust.

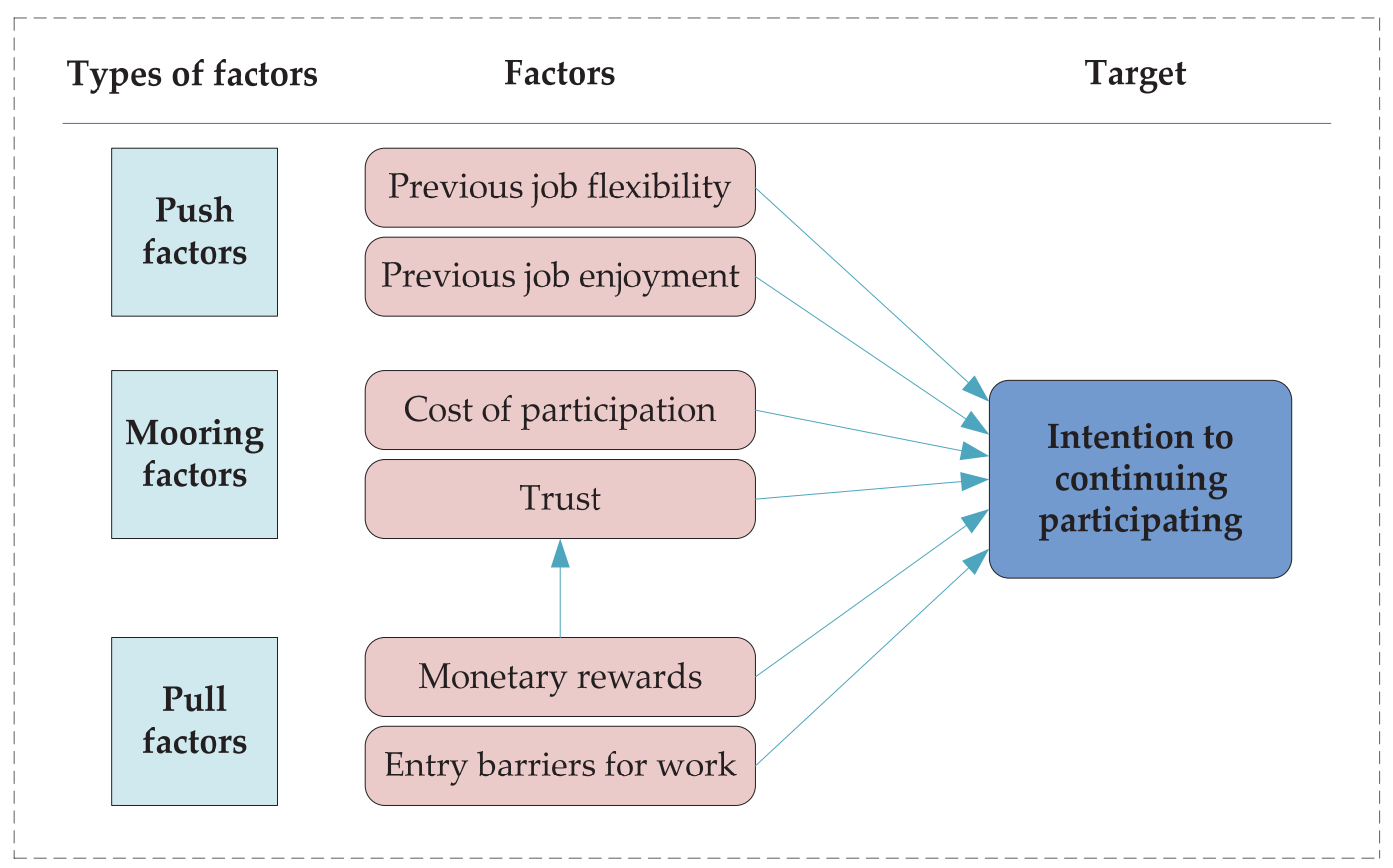

Figure 2. Research model for crowd workers' continued participation intention.

\subsection{Hypothesis}

This paper proposes several research hypotheses based on the three PPM aspects (push, pull, and mooring) and analyzed the specific factors that affect crowd workers' continued intentions to participate in crowd logistics. Push factors include flexibility and enjoyment from the previous job, pull factors include monetary rewards and entry barriers for work, while mooring factors include trust and the cost of participation.

\subsubsection{Push Factors}

Push factors mainly refer to the unfavorable and tedious aspects of the crowd workers' previous work. These negative factors drive crowd workers to continue participating in crowd logistics instead of returning to their previous jobs. In this study, the push factors include flexibility in the previous job and the enjoyment acquired from the previous job.

\section{(1) Previous job flexibility}

Studies show that job flexibility provides employees with balance and leisure, thereby increasing their work efficiency [45]. As a result, more and more companies have realized they can achieve sustained growth through flexible work schedules, particularly in the face of a tight labor market, an aging labor force, and excessive reliance on employees [46]. The need for flexibility is very relevant for participants of crowd logistics. But understanding how it affects people's motivations to remain on the platform requires further exploration. Previous studies have identified autonomy and flexibility as important reasons for people to leave their work and switch to crowd logistics [9,18,35]. In many cases, crowd workers' previous work (especially for those with full-time jobs) afforded limited flexibility in terms of work, coordination of work and family affairs, and self-motivation [47]. Based on these arguments, we propose the following hypothesis: 
H1: The lower the work flexibility of crowd workers' previous jobs, the stronger their intention to continue participating in crowd logistics.

(2) Previous job enjoyment

Crowd logistics, with its novel operation mode, unique delivery experience, and unconstrained working atmosphere, can provide additional enjoyment to crowd workers [37]. Since participation is on a voluntary basis, crowd workers can choose the logistics task(s) they wish to perform $[9,48]$. When the difficulty of the task matches one's ability, the crowd worker can complete the task with confidence and enjoy the process [49]. Other jobs (e.g., full-time, part-time and independent short-term contracts) may not be as flexible and autonomous as crowd logistics. In those work environments, tasks beyond the worker's personal abilities can cause anxiety and stress, which can subsequently result in job burnout [37]. Hence, we propose the following hypothesis:

H2: The lower the enjoyment of crowd workers' previous jobs, the stronger their intention to continue participating in crowd logistics.

\subsubsection{Mooring Factors}

Mooring factors mainly refer to elements that hinder or promote crowd workers' continued participation in crowd logistics. The mooring factors in this paper include the trust between the crowd worker and the platform (crowdsourcer) and the cost of participation.

(1) Trust

Trust can be earned when the platform (crowdsourcer) evaluates the crowd workers' solutions and rewards their work fairly [18], which could then serve as the basis for effective cooperation [50]. Previous studies have shown that trust is a vital factor that can influence crowd workers' participation in crowdsourcing [18,22]. It affects crowd workers' behavior and decision-making processes [51]. For example, a study by Shen et al. [26] found a person with a high level of trust in other Wikipedia contributors would be more likely to contribute to the community. However, due to potential risks in crowd logistics (e.g., delivery delays, extra costs, unclear distribution of responsibilities) [3] and inherent vulnerabilities in online activities [52], more effort is required to establish trust between the crowd worker and the platform (crowdsourcer). Therefore, we assume greater trust would encourage the crowd worker to continue in his/her participation in crowd logistics while facing potential risks. We propose the following hypothesis:

H3: The higher the trust between the crowd worker and the platform (crowdsourcer), the stronger the crowd worker's intention to continue participating in crowd logistics.

(2) Costs of participation

When the crowd worker participates in crowdsourcing activities, certain costs would inevitably be incurred [23]. These costs include money expenditure, time, and mental effort [53]. When a crowd worker participates in crowd logistics, he or she needs to provide transportation and learn the method of operation of the delivery software. Moreover, in order to provide customers with a more satisfactory service, the crowd worker would need to spend time and energy on training and practice. Since crowd logistics is still in its infancy [9], the existence of potential risks could indirectly increase costs for continued participation. Previous studies have shown that knowledge sharing could be viewed negatively as losing the knowledgeability edge and discourage individuals from future exchanges [18,54]. Based on these arguments, we propose the following hypothesis:

H4: The higher the participation cost, the lower the crowd worker's intention to continue participating in crowd logistics. 


\subsubsection{Pull Factors}

Pull factors refer to the positive and favorable factors in crowd logistics that encourage continued participation. In this study, the pull factors considered include monetary rewards and entry barriers for work.

(1) Monetary rewards

Studies have shown that for crowd logistics, external incentives serve as crucial driving factors for crowd workers' continued participation [9,37]. For instance, people may use their spare time to participate in crowd logistics in order to get additional income [37]. While money is not the only reason for crowd workers to engage in crowdsourcing, financial incentives are undeniably significant [32,55]. Due to the importance of monetary rewards in motivating people, some of the main challenges facing crowdsourcing platforms are related to finances, such as reasonable pricing, salary plans, and effective task allocation [56]. Crowdsourcing platforms need to provide the most appropriate compensation solution to encourage the continued participation of crowd workers [57]. Thus, monetary incentives are likely to be significant for the continued participation of crowd workers in crowd logistics and propose the following hypothesis:

H5: Monetary reward is positively correlated with crowd workers' continued participation in crowd logistics.

(2) Entry barriers for work

Since participation in crowdsourcing is voluntary and selective [3,6,48], crowd workers can have direct access to the job. As some scholars have pointed out, crowd workers can be self-employed, freelancers, or even unemployed [4,9]. In crowd logistics, as long as the crowd worker is familiar with operating a smartphone and is willing to spend a certain amount of time and energy, they can participate in the delivery. Unlike full-time logistics staff, crowd workers can participate in crowd logistics without having to undergo interviews, which provides them some degree of freedom and flexibility [18]. Based on these arguments, we propose the following hypothesis:

H6: Entry barriers for work are negatively correlated with crowd workers' continued participation in crowd logistics.

(3) The mediating effect of trust between monetary reward and crowd workers' continued participation

We predicted above that trust and monetary rewards will both have direct effects on crowd workers' continued participation in crowd logistics. Monetary rewards also have an indirect effect, in that workers' perception of fair compensation serves to increase their trust in the crowdsourcing platform [22,58], which, in turn, is likely to increase their participation intention. Crowd workers who do not feel they receive fair and equitable remuneration may show low-trust behavior and reduced willingness to participate [18]. Based on these arguments, we argue that trust between the crowd worker and the platform has a positive mediating effect on the monetary reward and propose the following hypothesis:

H7: The impact of monetary reward on crowd workers' continued participation within crowd logistics will be greater when trust in the platform is higher.

\section{Research Methodology and Results}

The purpose of this study is to investigate the factors influencing crowd workers' intentions to continue participating in crowd logistics. Based on the literature review, the model construction, and research hypotheses, the research process was developed and is presented in Figure 3. The research framework mainly includes the following five steps: 


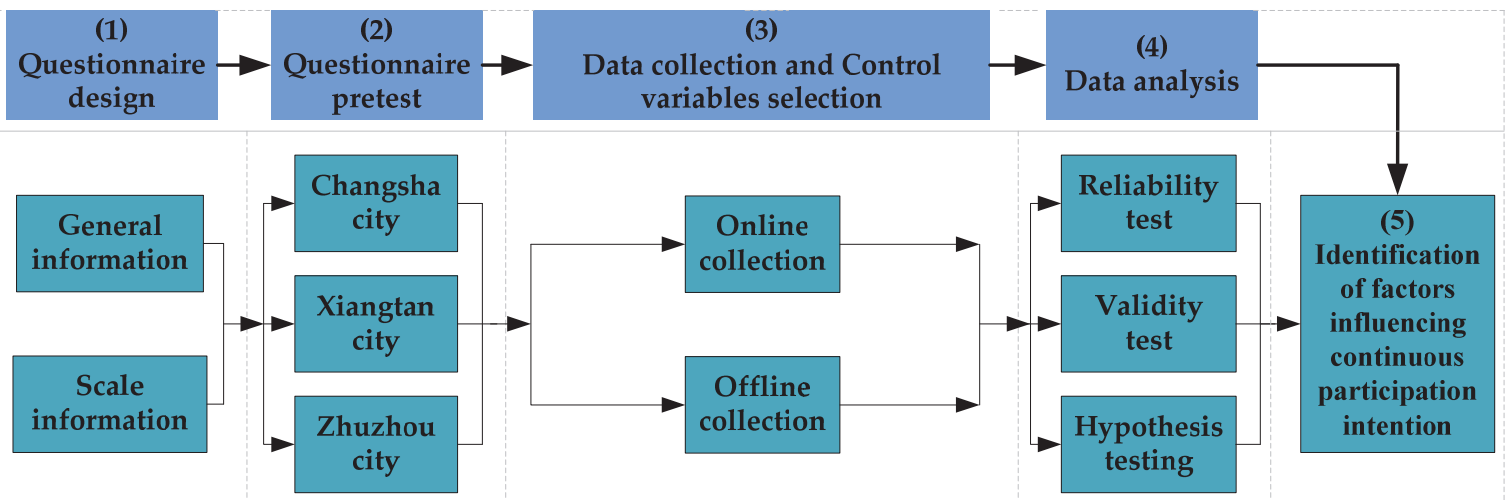

Figure 3. Research process.

\subsection{Questionnaire Design}

The questionnaire consisted of two parts: basic demographic information and validated scales for the key variables. The basic information section covered the respondent's gender, age, income, occupation, education, and length of time involved in crowd logistics. The scale information section included seven latent variables. A Likert scale was used to quantify the latent variables, and it consisted of five levels: (1) strongly disagree, (2) disagree, (3) neither agree nor disagree, (4) agree, and (5) strongly agree [59]. Meanwhile, each observable variable was connected to a specific latent variable, which was based on the findings and recommendations of previous studies, as summarized in Table 3.

Table 3. Item of constructs in the proposed model.

\begin{tabular}{|c|c|c|}
\hline Variables & Items & Reference \\
\hline \multirow{3}{*}{ Previous job flexibility (PJF) } & 1a: My previous job had very little flexibility. & \multirow{3}{*}{$\begin{array}{l}\text { Mladenow et al., } 2016 \text { [9]; Ye and } \\
\text { Kankanhalli, } 2017 \text { [18]; Lu et al., } \\
2008 \text { [47] }\end{array}$} \\
\hline & $\begin{array}{l}\text { 1b: Before participating in crowd logistics, I had a hard time } \\
\text { balancing the relationship between work and family. }\end{array}$ & \\
\hline & $\begin{array}{l}\text { 1c: I think my previous job hindered my autonomy in life } \\
\text { and work. }\end{array}$ & \\
\hline \multirow{2}{*}{ Previous job enjoyment (PJE) } & 2a: My previous job was boring. & \multirow{2}{*}{$\begin{array}{l}\text { Mladenow et al., } 2016 \text { [9]; Liang et al., } \\
2017 \text { [37] }\end{array}$} \\
\hline & 2c: My previous job was boring, and I often felt anxious. & \\
\hline \multirow[b]{2}{*}{ Trust (T) } & $\begin{array}{l}\text { 3a: I think the crowd logistics platform will give me a fair and just } \\
\text { monetary reward. }\end{array}$ & \multirow{2}{*}{$\begin{array}{l}\text { Ye and Kankanhalli, } 2017 \text { [18]; } \\
\text { Fellera et al., } 2012 \text { [22]; Shen et al., } \\
\text { 2014 [26] }\end{array}$} \\
\hline & 3b: I think the crowd logistics platforms will respect my schedule. & \\
\hline \multirow[t]{2}{*}{ Cost of participation (CoP) } & $\begin{array}{c}\text { 4b: I need to spend more time on learning and training about } \\
\text { crowd logistics. }\end{array}$ & \multirow{2}{*}{$\begin{array}{c}\text { Mladenow et al., } 2016 \text { [9]; Ye and } \\
\text { Kankanhalli, } 2017 \text { [18]; } \\
\text { Kankanhalli et al., } 2005 \text { [54] }\end{array}$} \\
\hline & $\begin{array}{c}\text { 4c: I need to provide my transportation to participate in } \\
\text { crowd logistics. }\end{array}$ & \\
\hline \multirow{3}{*}{ Monetary rewards (MR) } & 5a: Crowd logistics offers me the opportunity to make money. & \multirow{3}{*}{$\begin{array}{l}\text { Blohm et al., } 2018 \text { [55]; Gdowska et al., } \\
2018 \text { [56]; Archetti et al., } 2016 \text { [57] }\end{array}$} \\
\hline & $\begin{array}{c}\text { 5b: My monthly income increased by participating in } \\
\text { crowd logistics. }\end{array}$ & \\
\hline & $\begin{array}{c}\text { 5c: The more money I made, the more I wanted to get involved in } \\
\text { crowd delivery. }\end{array}$ & \\
\hline \multirow[b]{2}{*}{ Entry barriers for work (EBW) } & 6a: I can participate in crowd logistics as long as I want. & \multirow{2}{*}{$\begin{array}{l}\text { Punel et al., } 2018 \text { [4]; Mladenow et al., } \\
2016 \text { [9]; Ye and Kankanhalli, } 2017 \text { [18] }\end{array}$} \\
\hline & $\begin{array}{c}\text { 6b: It doesn't take any special skills to get involved in } \\
\text { crowd logistics. }\end{array}$ & \\
\hline
\end{tabular}




\subsection{Questionnaire Pretest}

To ensure the validity and reliability of the questionnaire, pretesting was conducted with 45 crowd workers selected randomly. The respondents were from our chosen test sites Changsha, Xiangtan, and Zhuzhou (15 respondents per city) and were contacted through mobile applications (WeChat or QQ). The pretest ran for two weeks and was completed in January 2019. Prior to pretesting, we first joined WeChat and QQ groups for crowd workers and randomly selected the participants. We inquired about their willingness to participate in our study, selected those who responded positively, and sent the questionnaire link through their personal accounts. We then conducted online interviews with five respondents from each city to determine whether they clearly understood the questions, and we asked for their suggestions for improvement. Each interview was generally completed within 10 to 15 minutes. Based on the results of the pretest and interviews, redundant items (specifically in the trust and monetary reward scales) were eliminated, and the language used in the questionnaire was refined and simplified so all respondents would be able to understand the questionnaire clearly.

\subsection{Data Collection and Control Variables Selection}

The research area included the Chinese cities of Changsha, Xiangtan, and Zhuzhou, which are located in Hunan province, as shown in Figure 4. In 2007, these cities were approved by the State Council as a "two-type (resource-conserving and environmentally friendly) society construction comprehensive supporting reform pilot area" [60]. Over the past decade, the urban agglomeration has embarked on a new path of industrialization and urbanization, different from the traditional pattern [60]. The focus has shifted towards coordinated development of the economy and the ecological environment and prescribed development concepts of innovation, coordination, green, open, and sharing. These concepts in economic development coincide well with the main principles of crowd logistics. In recent years, crowd logistics has developed rapidly in these areas, which were thus selected as the research area of our study.

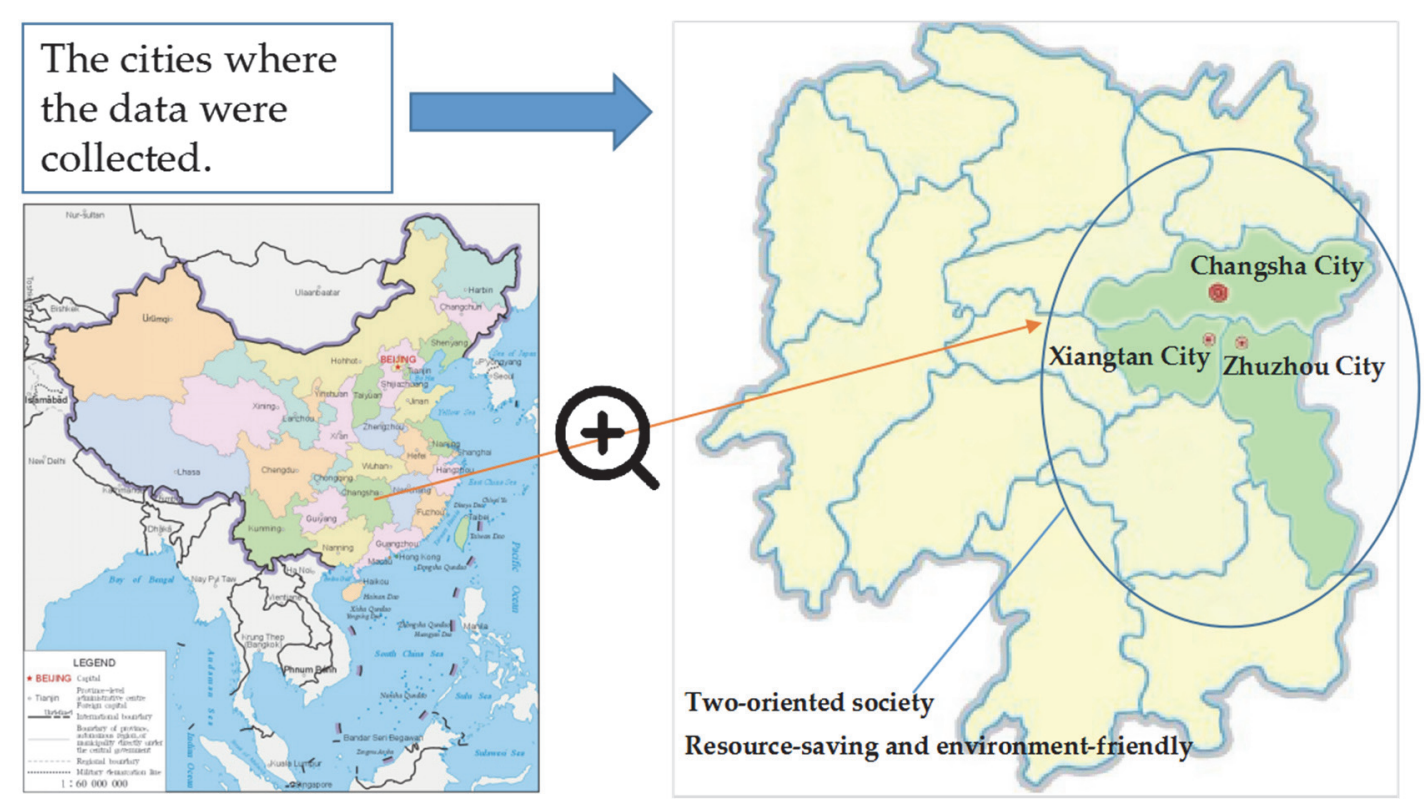

Figure 4. The urban agglomeration where the data were collected.

The survey was conducted online and offline. For the online mode, the questionnaires were sent through WeChat and QQ, while the offline part constituted in-person surveys with crowd workers. The average time it took to fill out the questionnaire was about 15 minutes. After completing the questionnaire, all online respondents were given a lucky draw with prizes ranging from two to five yuan. Offline respondents were given three packets of tissues worth three yuan after finishing 
the questionnaire. The survey lasted for six months from March 2019 to August 2019. A total of 650 questionnaires were issued, 519 were received, and 455 were deemed valid, giving a response rate of $87.67 \%$. Table 4 shows the detailed statistical results of the basic information section.

Table 4. Descriptive statistics of the crowd workers' basic information.

\begin{tabular}{|c|c|c|c|c|c|}
\hline Category & Item & Ratio & Category & Item & Ratio \\
\hline \multirow{2}{*}{ Gender } & Male & $92 \%$ & \multirow{5}{*}{$\begin{array}{l}\text { Income before } \\
\text { participating in crowd } \\
\text { logistics (monthly) }\end{array}$} & $<2000 \mathrm{RMB}$ & $12 \%$ \\
\hline & Female & $8 \%$ & & 2000-4000 RMB & $40 \%$ \\
\hline \multirow{5}{*}{ Age } & $18-25$ & $5 \%$ & & 4001-6000 RMB & $37 \%$ \\
\hline & $26-30$ & $13 \%$ & & 6001-8000 RMB & $7 \%$ \\
\hline & $31-35$ & $39 \%$ & & $>8000 \mathrm{RMB}$ & $4 \%$ \\
\hline & $36-40$ & $35 \%$ & \multirow{5}{*}{$\begin{array}{l}\text { Income while } \\
\text { participating in crowd } \\
\text { logistics (monthly) }\end{array}$} & $<2000 \mathrm{RMB}$ & $7 \%$ \\
\hline & $>40$ & $8 \%$ & & 2000-4000 RMB & $30 \%$ \\
\hline \multirow{4}{*}{ Education level } & $\leq$ Middle school & $36 \%$ & & 4001-6000 RMB & $46 \%$ \\
\hline & High school & $48 \%$ & & 6001-8000 RMB & $12 \%$ \\
\hline & junior college & $11 \%$ & & $>8000 \mathrm{RMB}$ & $5 \%$ \\
\hline & $\geq$ Bachelors & $5 \%$ & \multirow{5}{*}{ Previous occupation } & Factory workers & $7 \%$ \\
\hline \multirow{4}{*}{$\begin{array}{l}\text { Duration of participation } \\
\text { in crowd logistics }\end{array}$} & $<$ Half a year & $43 \%$ & & Freelancer & $30 \%$ \\
\hline & 0.5 to 1 year & $27 \%$ & & $\begin{array}{l}\text { Formal staff in the } \\
\text { logistics industry }\end{array}$ & $22 \%$ \\
\hline & 1 to 1.5 year & $21 \%$ & & Unemployed & $33 \%$ \\
\hline & $>1.5$ years & $9 \%$ & & Other & $8 \%$ \\
\hline
\end{tabular}

We included the basic information of crowd workers as control variables in the research model. These variables include respondents' gender, age, education, duration of participation in crowd logistics, and previous occupation. These are treated as control variables by many scholars (e.g., Ye and Kankanhalli, 2017 [18]; Liang et al., 2017 [37]; Shen et al., 2014 [26]). The previous occupation refers to the work experience of crowd workers. Since each crowd worker may have different work experience, this may affect the crowd workers' participation in crowd logistics. The basic information of crowd workers is summarized in Table 4. The respondents were mainly male, aged between 30 and 40, and with relatively low education levels. The respondents are mainly on low incomes, and most of them have no fixed jobs. After participating in crowd delivery, the respondents' monthly income generally increases. Only $30 \%$ of the respondents have been participating in crowd delivery for at least one year. This confirms that motivating crowd workers to continue participating in crowd logistics is of vital importance.

\subsection{Data Analysis}

We used SmartPLS3.0 software to conduct the analysis. Based on the principle of structural equation modeling (SEM), the software can simultaneously estimate the measurement indicators and latent variables in the model and employ statistical analysis for large samples [61]. Partial least squares structural equation modeling (PLS-SEM) is a mathematical model that provides an objective representation suitable for multi-stage model processing [62]. It can be used to test the hypothesis relationship between observed and latent variables and has been widely used in the fields of behavioral and social sciences [61].

For example, Sebastian et al. [63] explored the strategic supply chain management's mediating effect on sustainable operations through environmental and social sustainability, using smart partial least square structural equation modeling (SmartPLS-SEM). Nania and Sulung [64] used Partial Least Squares (PLS) to study the impact of backers' activeness, entrepreneurs' activeness, and entrepreneurs' reputations on the fundraising performance of crowdfunding projects in developing 
countries. Their research shows SmartPLS can be used to analyze the influencing factors of crowd workers' participative behavior. The various usage of this method in the field of behavioral and social sciences further confirms the applicability and sustainability of SmartPLS.

\subsubsection{Reliability and Validity Test}

The scale and the constructed model were tested for reliability and validity [42]. As shown in Table 5, the Cronbach's alpha (CA) (>0.7), Combinatorial Reliability (CR) $(>0.7)$, and Average Variance Extracted (AVE) (>0.7) of each latent variable all met the relevant thresholds; the value of outer loading on each observation variable in Figure A1 is greater than 0.7 (the minimum is 0.725) [65]. As presented in Table 6, the AVE square root is larger than the correlation coefficient between it and other latent variables, which indicates that the discriminant validity of the research model is very good, and there is no multicollinearity between the latent variables [66].

Table 5. Results of reliability and validity tests.

\begin{tabular}{cccc}
\hline Construct & CA & CR & AVE \\
\hline CPI & 0.875 & 0.923 & 0.800 \\
PJF & 0.794 & 0.879 & 0.708 \\
PJE & 0.857 & 0.913 & 0.778 \\
T & 0.727 & 0.847 & 0.649 \\
CoP & 0.775 & 0.870 & 0.691 \\
MR & 0.760 & 0.862 & 0.676 \\
EBW & 0.927 & 0.954 & 0.873 \\
\hline
\end{tabular}

Note: continued participation intention (CPI), previous job flexibility (PJF), previous job enjoyment (PJE), trust (T), cost of participation (CoP), monetary rewards (MR), entry barriers for work (EBW).

Table 6. Average Variance Extracted (AVE) square root and factor correlation coefficient.

\begin{tabular}{clllllll}
\hline & $\mathbf{H}$ & $\mathbf{H 1}$ & $\mathbf{H 2}$ & $\mathbf{H 3}$ & $\mathbf{H} 4$ & $\mathbf{H} 5$ & H6 \\
\hline CPI & $\mathbf{0 . 8 9 5}$ & & & & & & \\
PJF & 0.324 & $\mathbf{0 . 8 4 2}$ & & & & & \\
PJE & -0.339 & -0.016 & $\mathbf{0 . 8 8 2}$ & & & & \\
T & 0.721 & 0.380 & -0.273 & $\mathbf{0 . 8 0 6}$ & & & \\
CoP & 0.439 & 0.589 & -0.021 & 0.522 & $\mathbf{0 . 8 3 1}$ & & \\
MR & 0.651 & 0.366 & -0.132 & 0.709 & 0.449 & $\mathbf{0 . 8 2 2}$ & \\
EBW & -0.191 & 0.035 & 0.088 & -0.101 & -0.041 & -0.131 & $\mathbf{0 . 9 3 4}$ \\
\hline
\end{tabular}

Notes: diagonal elements are the square root of Average Variance Extracted (AVE).

In order to eliminate the effect of common method bias (CMB) [66], this study utilized program control and statistical testing [67]. First, to eliminate the psychological burden, the respondents were told their identities would be kept anonymous, their responses were only to be used for academic research, and the results would not affect their work. Also, as mentioned earlier, we used pretesting to ensure that each item could be easily and clearly understood by the respondents. Finally, Harman's single factor test was adopted to perform an exploratory factor analysis on all variables [67]. The test results are shown in Table 7 . The results show that no single factor was generated, nor could a single factor explain most of the variability ( $>40 \%$ ). Therefore, based on the above two aspects, there is no problem of common method bias in our study. 
Table 7. Total variance explained.

\begin{tabular}{ccccccc}
\hline \multirow{2}{*}{ Component } & \multicolumn{3}{c}{ Initial Eigenvalues } & \multicolumn{2}{c}{ Extraction Sums of Squared Loadings } \\
\cline { 2 - 6 } & Total & \% of Variance & Cumulative \% & Total & \% of Variance & Cumulative \% \\
\hline 1 & 6.740 & 32.097 & 32.097 & 6.740 & 32.097 & 32.097 \\
2 & 2.913 & 13.870 & 45.967 & 2.913 & 13.870 & 45.967 \\
3 & 2.356 & 11.217 & 57.184 & 2.356 & 11.217 & 57.184 \\
4 & 1.619 & 7.709 & 64.893 & 1.619 & 7.709 & 64.893 \\
5 & 0.885 & 4.216 & 69.109 & & & \\
\hline
\end{tabular}

\subsubsection{Hypothesis Testing}

In order to test the proposed hypotheses, we constructed a model (shown in the appendices, Figure A1) and performed hypothesis testing with bootstrapping using SmartPLS3.0 software. The results are shown in Table 8. The model's $\mathrm{R}^{2}$ (R-squared) is 0.6 , indicating that the generated model has a high explanatory capacity [65]. Moreover, using the verification results as presented in Table 8, the hypotheses H2, H3, H5, H6, and H7 passed the hypothesis tests (p-value $\leq 0.05$ [65]), while $\mathrm{H} 1$ and $\mathrm{H} 4$ were not confirmed (p-value $>0.05$ [65]).

Table 8. Results of hypotheses testing.

\begin{tabular}{cccccc}
\hline Hypothesis & Path & Path Coefficient & $\boldsymbol{t}$-Value & $\boldsymbol{p}$-Value & Hypothesis Supported? \\
\hline $\mathrm{H} 1$ & $\mathrm{PJF} \rightarrow \mathrm{CPI}$ & 0.018 & 0.414 & 0.679 & $\mathrm{~N}$ \\
$\mathrm{H} 2$ & $\mathrm{PJE} \rightarrow \mathrm{CPI}$ & -0.178 & 5.494 & 0.000 & $\mathrm{Y}$ \\
$\mathrm{H} 3$ & $\mathrm{~T} \rightarrow \mathrm{CPI}$ & 0.420 & 7.383 & 0.000 & $\mathrm{Y}$ \\
$\mathrm{H} 4$ & $\mathrm{CoP} \rightarrow \mathrm{CPI}$ & 0.078 & 1.754 & 0.080 & $\mathrm{~N}$ \\
$\mathrm{H} 5$ & $\mathrm{MR} \rightarrow \mathrm{CPI}$ & 0.276 & 6.124 & 0.000 & $\mathrm{Y}$ \\
$\mathrm{H} 6$ & $\mathrm{EBW} \rightarrow \mathrm{CPI}$ & -0.095 & 3.356 & 0.001 & $\mathrm{Y}$ \\
$\mathrm{H} 7$ & $\mathrm{MR} \rightarrow \mathrm{T}$ & 0.709 & 24.524 & 0.000 & $\mathrm{Y}$ \\
\hline
\end{tabular}

\subsection{Findings}

\subsubsection{Significant Influence Factors}

(1) The enjoyment of the previous job has a significant negative impact on the willingness to continue participating in crowd logistics. This is consistent with previous research by Mladenow et al. [9], Liang et al. [37], and Nakamura and Csikzentmihalyi [49]. Crowd logistics workers can freely choose the delivery task and working time [18,35], and engage with different customers. This level of flexibility and opportunity for new experiences can provide satisfaction and meet the needs of self-realization [37]. The prospect of returning to the monotony and tediousness of their old jobs can push people to continue participating in crowd logistics;

(2) Trust was shown to have a significant positive impact on continued participation in crowd logistics, which supports the conclusions of some previous studies [18,22,26]. In crowd logistics, potential risks exist for both the crowd worker and the platform with regard to responsibility distribution, delivery delays, and possible loss or damage of goods [3]. The handling of such risks can directly affect crowd workers' trust in the platform, which could thereby affect their willingness to continue participating in the system. In general, the crowd logistics platform is expected to assume responsibility and deal with complicated problems encountered in the delivery process (e.g., traffic accidents and cargo compensation). If the platform is able to solve these complex problems and reduce participation risks, crowd workers would be more inclined to continue participating in crowd logistics;

(3) Monetary rewards have a significant positive impact on the willingness of crowd workers to continue participating in crowd logistics, which is consistent with the findings of related research $[9,32,37,55]$. Monetary reward is likely to be a crucial driving factor for people to continue 
working in crowd logistics, particularly for the demographic profile of our sample-mostly people on low incomes (52\%) and/or with no fixed job (63\% or more);

(4) Entry barriers for work have a negative impact on the willingness of crowd workers to continue participating in crowd logistics - the impact is small (-0.095) but statistically significant. Since crowd logistics has a lower access threshold, it encourages initial participation among crowd workers [3,4]; one of the appeals of crowd logistics platforms is having minimal impediments for participation-a person who wishes to apply can quickly become eligible for admission, no matter the participant's previous job experience [48]. This has, however, raised some concerns, with Rai et al. [14] and Chen et al. [68] arguing that the low entry threshold could aggravate the uncertainties of the crowd worker, while the platform would hardly be able to control the quality and service. The low procedural impediments can motivate people's initial participation in crowdsourcing, but can also yield potential uncertainties and risks which may make them less likely to continue to participate;

(5) Trust plays an intermediary role in influencing how monetary rewards affect continued participation in crowd logistics. A previous study by Ye and Kankanhalli [18], which surveyed 156 crowd workers from the TaskCN platform, showed that trust in crowdsourcing platforms promote people's willingness to continue participating and can amplify the effects of monetary rewards. Our results confirmed this conclusion and found it to be applicable in the field of crowd logistics.

\subsubsection{Non-Significant Influence Factors}

(1) Flexibility in previous jobs did not show a significant impact on the willingness to continue participating in crowd logistics, contrary to the findings of previous studies on crowdsourcing $[9,18,26,35]$. This may be because crowd logistics work is different from information crowdsourcing in a general sense, and the participants are mostly low-income people without fixed jobs [4]. Before they participated in crowd logistics, most had a lot of free time to spend with family or for leisure purposes. Their participation in crowd logistics is thus motivated by a desire to get a job/higher income job for financial reasons, and this motivation supersedes concerns for work-life balance or flexibility in the work environment;

(2) Our study costs associated with participation—cognitive effort, currency, time, and mental effort-did not show any significant impact on people's motivation to continue working in crowd logistics. This is in contrast to previous studies [18,54], which found that cognitive effort (part of participation costs) has a significant negative correlation with continued participation in crowdsourcing. One possible explanation is that crowd logistics is easier to learn and implement compared to some other forms of crowdsourcing work, e.g., network crowdsourcing designed by innovative solutions.

\section{Discussion}

Our findings show support for five of the seven hypotheses we developed from the literature regarding the impact of key variables on crowd workers' intentions to continue participating in crowd logistics work. Monetary rewards and trust proved to be by far the most important variables, and, of course, both can be directly influenced by crowd logistics platforms. Previous job enjoyment is negatively related to continued participation intention, i.e., crowd workers who had been unhappy in their previous jobs are more likely to stick with crowd logistics. There was also a significant but very small negative correlation between entry barriers for work and continued participation. These findings are consistent with the existing literature, and we might expect to find similar results in other settings. Based on these findings, we proposed the following theoretical and practical implications.

\subsection{Theoretical Implications}

Based on PPM theory, we developed an influencing factor model, which can be used to characterize crowd workers' willingness to continue participating in crowd logistics. This study has three main theoretical contributions. First, it enriches the literature on crowd logistics. The sustainability of urban logistics has become a popular research theme, especially in environmental pollution 
(e.g., Guerlain et al., 2019 [69]; Kiba-Janiak and Witkowski, 2019 [70]; Keyju et al., 2019 [71]), however little research has focused on the sustainable development of urban crowd logistics from the perspective of crowd workers (e.g., Punel et al., 2018 [4]; Rai et al., 2017 [14]; Arslan et al., 2019 [25]). By focusing on the viewpoint of the crowd workers and analyzing the various factors influencing their participation, this paper provides an innovative perspective and can serve as an essential reference for crowd logistics platforms seeking to develop appropriate incentives.

Second, this study provided a comprehensive examination of factors affecting the continued participation of crowd workers, based on three types of factors: push, pull, and mooring. The approach differs from existing research that generally evaluated the influencing factors through case analysis (e.g., Mladenow et al., 2015 [3]; Rai et al., 2017 [14]; Horton and Chilton, 2010 [32]) and simulations (e.g., Chen and Chankov, 2017 [7]; Arslan, et al., 2019 [25]). Based on our model of "Push-Pull-Mooring" factors, we were able to distinguish the factors that motivate crowd workers and demonstrate the mediating effect of trust between monetary rewards and the willingness to continue participating in crowd logistics.

Third, this study demonstrates that PPM theory offers a robust framework for identifying and studying the factors affecting the willingness for continued participation in crowd logistics, which also contributes to the gradual extension of PPM theory from demography to other disciplines [39-44].

\subsection{Practical Implications}

From a practical perspective, the insights provided by our study allow us to offer recommendations for crowd logistics platforms and relevant enterprises to formulate reasonable measures that would encourage continued participation. There are four practical implications of the study.

First, crowd logistics platforms should constantly review their monetary incentives. This paper found monetary rewards have a significant positive correlation with the willingness to continue participating in crowd logistics. However, a singular and unchanging mode of monetary compensation has a limited incentive effect on crowd workers' continued participation [3]. Crowd logistics platforms should be able to offer appropriate monetary compensation and incentivize performance and increased participation (e.g., offer additional rewards online based on the number of orders the crowd worker completes each day).

Second, crowd logistics platforms should take the initiative in seeking to build a high degree of trust and long-term cooperation among existing and potential crowd workers. We found that trust is positively correlated with the willingness to continue participating in crowd logistics. However, potential participation risks, such as financial instability, lack of social security, and isolation, can bring uncertainties and stress, which could induce crowd workers to change jobs [34]. It is, therefore, incumbent upon the crowd logistics platform to provide economic and psychological support and build trust among its crowd workers.

Third, crowd logistics platforms should promote worker enjoyment through various meaningful activities. Our findings indicate a significant negative correlation between previous work enjoyment and the willingness to continue participating in crowd logistics. Liang et al. [37] believe the novel operation mode, unique delivery experience and unconstrained working atmosphere of crowd logistics can increase worker enjoyment. Crowd logistics platforms can try implementing enjoyable activities like the online lottery, corporate parties, training opportunities, and other offline activities.

Finally, the low entry barriers for work (EBW) associated with crowd logistics make controlling the crowd workers' quality and service difficult. Although the lower entry threshold is conducive to crowd workers' continued participation, it exacerbates the uncertainty of crowd workers $[14,68]$. Our study showed that EBW was negatively correlated with crowd workers' continued participation in crowd logistics, though the effect size was small. This suggests raising entry barriers would have a small positive impact on retaining crowd workers. However, given that higher EBW would have a negative impact on recruiting crowd workers, the overall impact might be neutral or even negative. Crowd logistics platforms would thus need to exercise judgment on what is most appropriate for their 
situation, e.g., a platform that found workers easy to recruit but hard to retain might gain benefits from raising their entry barriers.

\section{Conclusions}

The emergence and rapid growth of crowd logistics represents an important response to the last-mile delivery challenge, which makes the continued participation of crowd workers a key issue in today's logistics industry. However, motivating continued participation in crowd logistics has some challenges, which could worsen if these issues are not addressed. In order to understand the underlying factors behind crowd workers' motivations, we developed and implemented a new model based on the Push-Pull-Mooring theory. Our empirical results show monetary rewards and trust are strongly and positively correlated with continued participation in crowd logistics, while enjoyment from previous work and entry barriers have a significant negative correlation. Trust has a mediating effect on how monetary incentives influence crowd workers' willingness to continue working in crowd logistics. The findings of this study contribute to the growing literature on crowd logistics.

Based on the findings of this study, we recommend that crowd logistics platforms should offer reasonable monetary incentives and keep these under constant review, build a high degree of trust and cooperation with their crowd workers, and initiate activities geared towards promoting satisfaction at work. The recommendations based on the results of this study can help crowd logistics platforms formulate suitable policies and implement measures that would encourage continued participation in crowd logistics.

However, we should acknowledge that our study has some limitations. First, the survey data comes from an urban agglomeration in South Central China, the characteristics of which may be very different from other settings. This is a challenge for all studies of crowd logistics, as geographical location is obviously a significant influence on how crowd logistics operate on the ground. It would, therefore, be necessary to conduct further studies for different regions and countries to compare with the results of this study. Second, many of our participants were in low-income jobs, with one-third of them being unemployed. We cannot know if this is typical of crowd logistics workers, though it seems possible; clearly, further research is required. Although there is a body of research developing on crowd workers generally, the demographic profile of such workers is likely to be very diverse, and logically each type of crowdsourced work may attract a different demographic, reflecting the differing expertise involved and the different entry barriers. The research on crowd logistics is still in its infancy, and research on many other aspects regarding crowd workers, platforms, consumers, and related enterprises are needed to support the sustainable development of the crowd logistics industry.

Author Contributions: Methodology, G.X.; software, G.X.; validation, G.X., L.H. and H.B.; formal analysis, J.B., H.B. and G.X.; investigation, H.B.; resources, L.H.; data curation, H.B. and G.X.; writing-original draft preparation, G.X; writing—review and editing, J.B. and R.H.; supervision, L.H. All authors have read and agreed to the published version of the manuscript.

Funding: This research was funded by National Social Science Foundation Project under grant number 15BGL201, the MOE (Ministry of Education in China) Project of Humanity and Social Science Foundation under grant number 18YJA630001 and Guangzhou Think Tank Foundation Project under grant number 2018CZZK23.

Acknowledgments: The authors thank the editor and anonymous reviewers for their numerous constructive comments and encouragement that have improved our paper greatly. Thanks to the professional English editing service from EditX.

Conflicts of Interest: The authors declare no conflict of interest. 


\section{Appendix A}

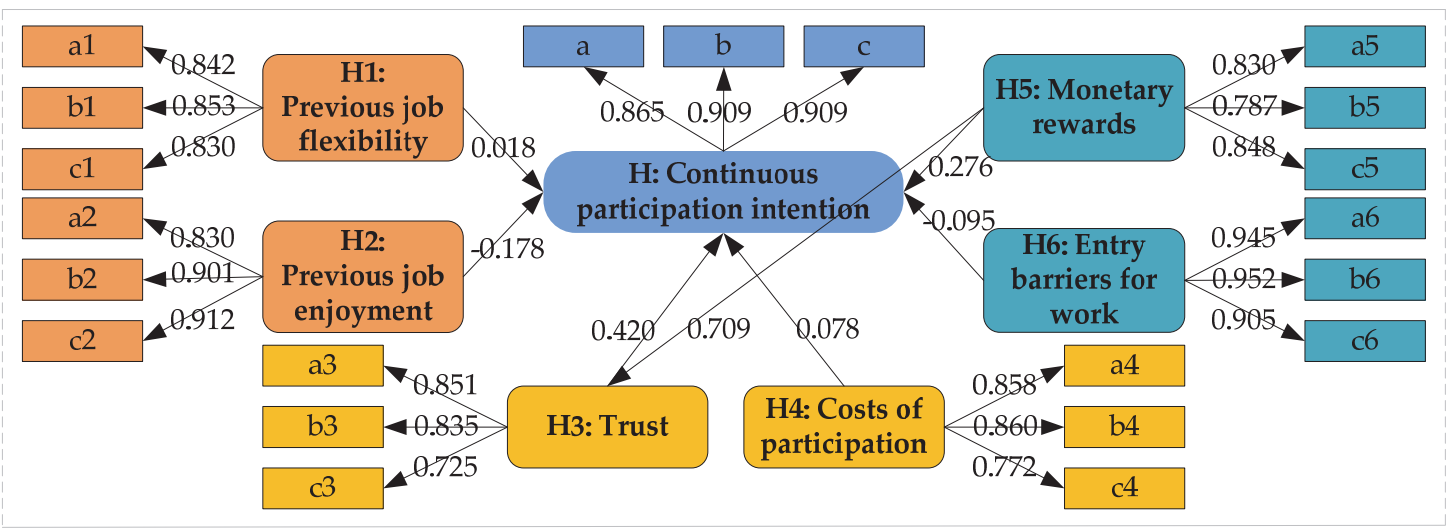

Figure A1. The model results, showing individual items.

\section{References}

1. Zervas, G.; Proserpio, D.; Byers, J. The Rise of the Sharing Economy: Estimating the Impact of Airbnb on the Hotel Industry. J. Market. Res. 2017, 54, 687-705. [CrossRef]

2. Habibi, M.R.; Davidson, A.; Laroche, M. What Managers Should Know About the Sharing Economy. Bus. Horizons. 2017, 60, 113-121. [CrossRef]

3. Mladenow, A.; Bauer, C.; Strauss, C. Crowdsourcing in Logistics: Concepts and Applications Using the Social Crowd. Proc. of the 17th International Conference on Information Integration and Web-based Applications \& Services (iiWAS2015). ACM 2015, 244-251. [CrossRef]

4. Punel, A.; Ermagun, A.; Stathopoulos, A. Studying Determinants of Crowd-shipping Use. Travel. Behav. Soc. 2018, 12, 30-40. [CrossRef]

5. Howe, J. The rise of crowdsourcing. Wired Mag. 2006, 14, 176-183.

6. Ranard, B.L.; Ha, Y.P.; Meisel, Z.F.; Asch, D.A.; Hill, S.S.; Becker, L.B.; Merchant, R.M. Crowdsourcing-Harnessing the Masses to Advance Health and Medicine, a Systematic Review. J. Gen. Intern. Med. 2014, 29, 187-203. [CrossRef]

7. Chen, P.; Chankov, S.M. Crowdsourced Delivery for Last-mile Distribution: An Agent-based Modelling and Simulation Approach. In Proceedings of the 2017 IEEE International Conference on Industrial Engineering and Engineering Management (IEEM), Singapore, 10-13 December 2017; pp. 1271-1275. [CrossRef]

8. Ha, T.; Esper, T.L.; Rossiter, H.A. Designing Crowdsourced Delivery Systems: The Effect of Driver Disclosure and Ethnic Similarity. J. Oper. Manag. 2018, 60, 19-33.

9. Mladenow, A.; Bauer, C.; Strauss, C. 'Crowd Logistics': The Contribution of Social Crowds in Logistics Activities. Int. J. Web. Inform. Syst. 2016, 12, 379-396. [CrossRef]

10. Hangzhou Weikedao Technology Co., Ltd. Take Stock of 7 Crowdsourcing Logistics Companies in China, the City is Full of Couriers. Available online: http://www.shunjian8.com/ydds/5774.html (accessed on 25 September 2019).

11. Renren Express Co., Ltd. Enterprise Profile. Available online: https://www.rrkd.cn/about/company\#pos-tabs (accessed on 25 September 2019).

12. Pourhejazy, P.; Kwon, O.K.; Chang, Y.T.; Park, H.K. Evaluating Resiliency of Supply Chain Network: A Data Envelopment Analysis Approach. Sustainability 2017, 9, 255. [CrossRef]

13. Devari, A.; Nikolaev, A.G.; He, Q. Crowdsourcing the Last Mile Delivery of Online Orders by Exploiting the Social Networks of Retail Store Customers. Transport. Res. E-Log. 2017, 105, 105-122. [CrossRef]

14. Rai, H.B.; Verlinde, S.; Merckx, J. Macharis, Cathy. Crowd Logistics: An Opportunity for More Sustainable Urban Freight Transport? Eur. Transp. Res. Rev. 2017, 9, 1-13.

15. Melo, S.; Macharis, C. City Distribution and Urban Freight Transport: Multiple Perspectives; Edward Elgar Publishing: Cheltenham, UK, 2011.

16. Wang, Y.; Zhang, D.; Liu, Q.; Shen, F.; Lee, L.H. Towards Enhancing the Last-mile Delivery: An Effective Crowd-tasking Model with Scalable Solutions. Transport. Res. E-Log. 2016, 93, 279-293. [CrossRef] 
17. Bayus, B.L. Crowdsourcing New Product Ideas over Time: An Analysis of the Dell IdeaStorm Community. Manag. Sci. 2013, 59, 226-244. [CrossRef]

18. Ye, H.; Kankanhalli, A. Solvers' Participation in Crowdsourcing Platforms: Examining the Impacts of Trust, and Benefit and Cost Factors. J. Strateg. Inform. Syst. 2017, 26, 101-117. [CrossRef]

19. Guo, J.; Wang, J.W.; Yan, Z.Y. Motivation and Factors Effecting the Participation Behavior in the Urban Crowdsourcing Logistics-Evidence from China. In Proceedings of the 10th International Conference on E-Education, E-Business, E-Management and E-Learning, Tokyo, Japan, 10-13 January 2019; pp. 334-341. [CrossRef]

20. Boons, M.; Stam, D.; Barkema, H.G. Feelings of Pride and Respect as Drivers of Ongoing Member Activity on Crowdsourcing Platforms. J. Manag. Stud. 2015, 52, 717-741. [CrossRef]

21. Schreieck, M.; Pflügler, C.; Dehner, C.; Vaidya, S.; Bönisch, S.; Wiesche, M.; Krcmar, H. A Concept of Crowdsourced Delivery for Small Local Shops. Informatic 2016, 375-384.

22. Fellera, J.; Finnegan, P.; Hayesa, J.; O’Reilly, P. 'Orchestrating' Sustainable Crowdsourcing: A Characterisation of Solver Brokerages. J. Strategic. Inf. Syst. 2012, 21, 216-232. [CrossRef]

23. Afuah, A.; Tucci, C.L. Crowdsourcing as A Solution to Distant Search. Acad. Manag. Rev. 2012, 37, 355-375. [CrossRef]

24. Carbone, V.; Rouquet, A.; Roussat, C. The Rise of Crowd Logistics: A New Way to Co-Create Logistics Value. J. Bus. Log. 2017, 38, 238-252. [CrossRef]

25. Arslan, A.M.; Agatz, N.; Kroon, L.; Zuidwijk, R. Crowdsourced Delivery-A Dynamic Pickup and Delivery Problem with Ad Hoc Drivers. Transport. Sci. 2019, 53, 222-235. [CrossRef]

26. Shen, X.L.; Lee, M.K.O.; Cheung, C.M.K. Exploring Online Social Behavior in Crowdsourcing Communities: A Relationship Management Perspective. Comput. Hum. Behav. 2014, 40, 144-151. [CrossRef]

27. Ye, H.; Feng, Y.; Choi, B. Understanding Knowledge Contribution in Online Communities from the Perspective of Community Support and Leader Support. Electron. Commer. Res. Appl. 2015, 14, 34-45. [CrossRef]

28. Howe, J. Crowdsourcing: Why the Power of the Crowd is Driving the Future of Business; Crown Publishing Group: New York, NY, USA, 2008. [CrossRef]

29. Estelles-Arolas, E.; Gonzalez-Ladron-De-Guevara, F. Towards an Integrated Crowdsourcing Definition. J. Inf. Sci. 2012, 38, 189-200. [CrossRef]

30. Doan, A.; Ramakrishnan, R.; Halevy, A.Y. Crowdsourcing Systems on the World-Wide Web. Commun. ACM 2011, 54, 86-96. [CrossRef]

31. Hosseini, M.; Phalp, K.; Taylor, J.; Ali, R. The Four Pillars of Crowdsourcing: A Reference Model. In Proceedings of the 2014 IEEE Eighth International Conference on Research Challenges in Information Science (RCIS), Marrakech, Morocco, 28-30 May 2014. [CrossRef]

32. Horton, J.; Chilton, L. The Labor Economics of Paid Crowdsourcing. In Proceedings of the 11th ACM Conference on Electronic Commerce, Cambridge, MA, USA, 7-11 June 2010. [CrossRef]

33. Lusch, R.F.; Brown, S.W.; Brunswick, G.J. A General Framework for Explaining Internal vs. External Exchange. J. Acad. Market Sci. 1992, 20, 119-134. [CrossRef]

34. De Groen, W.; Maselli, I. The Impact of the Collaborative Economy on the Labour Market. Available online: https://www.ceps.eu/ceps-publications/impact-collaborative-economy-labour-market/ (accessed on 18 September 2019).

35. Rougès, J.F.; Montreuil, B. Crowdsourcing Delivery: New Interconnected Business Models to Reinvent Delivery. In Proceedings of the 1st International Physical Internet Conference, Québec City, QC, Canada, 28-30 May 2014; pp. 1-19. Available online: http://www.cirrelt.ca/IPIC2014/PDF/1027A.pdf (accessed on 16 September 2019).

36. Deng, X.; Joshi, K.D.; Galliers, R.D. The Duality of Empowerment and Marginalization in Microtask Crowdsourcing: Giving Voice to the Less Powerful Through Value Sensitive Design. Mis. Quart. 2016, 40, 279-302. [CrossRef]

37. Liang, X.B.; Huang, L.X.; Jiang, J. Research on Antecedent Factors of Solvers' Continued Participation in Crowdsourcing Logistics. J. Bus. Econ. 2017, 5-15. [CrossRef]

38. Geri, N.; Gafni, R.; Bengov, P. Crowdsourcing as a Business Model: Extrinsic Motivations for Knowledge Sharing in User-generated Content Websites. J. Glob. Oper. Strateg. Src. 2017, 10, 90-111. [CrossRef]

39. Jung, J.; Han, H.; Oh, M. Travelers' Switching Behavior in the Airline Industry from the Perspective of the Push-Pull-Mooring Framework. Tourism. Manag. 2017, 59, 139-153. [CrossRef] 
40. Bansal, H.S.; Taylor, S.F.; James, Y.S. “Migrating” to New Service Providers: Toward a Unifying Framework of Consumers' Switching Behaviors. J. Acad. Market. Sci. 2005, 33, 96-115. [CrossRef]

41. Lee, E.S. A Theory of Migration. Demography 1966, 3, 47-57. [CrossRef]

42. Tang, D.; Yang, Y.; Yan, Y.; Zhou, M. What Determines Online Consumers to Migrate from PCs to Mobile Devices? - An Empirical Approach on Consumers' Internet Cross-channel Behaviours. Int. J. Serv. Technol. Manag. 2016, 22, 46-62. [CrossRef]

43. Leng, P. An Empirical Study on Switching Behavior in Cambodia's Mobile Telecommunication Service. J. Inform. Commun. Res. 2014, 32, 13-26.

44. Bin, H.; Wang, H.F.; Xie, G.J. Study on the Influencing Factors of Crowdsourcing Logistics under Sharing Economy. Manag. Rev. 2019, 31, 219-229. [CrossRef]

45. Dawkins, P.; Simpson, M. Work, Leisure and the Competitiveness of Australian Industry. Int. J. Manpower. 1994, 15, 38-76. [CrossRef]

46. Westerman, A. The Relation Between Corporate Training and Development Expenditures and the Use of Temporary Employees. Ethics Behav. 2001, 11, 67-86. [CrossRef]

47. Lu, L.; Kao, S.F.; Chang, T.T.; Wu, H.P.; Cooper, C.L. Work/Family Demands, Work Flexibility, Work/Family Conflict, and Their Consequences at Work: A National Probability Sample in Taiwan. Int. J. Stress Manag. 2008, 15, 1-21. [CrossRef]

48. Guo, B.; Chen, C.; Yu, Z.; Zhang, D.Q.; Zhou, X.S. Building Human-Machine Intelligence in Mobile Crowd Sensing. IT Prof. 2015, 17, 46-52. [CrossRef]

49. Nakamura, J.; Csikzentmihalyi, M. The construction of meaning through vital engagement. In Flourishing: Positive Psychology and the Life Well-Lived; Keyes, C.L.M., Haidt, J., Eds.; American Psychological Association: Washington, DC, USA, 2003; pp. 83-104.

50. Deutschi, M. The Effect of Motivational Orientation upon Trust and Suspicion. Hum. Relat. 1960, 13, $123-139$. [CrossRef]

51. Morgan, R.M.; Hunt, S.D. The Commitment-Trust Theory of Relationship Marketing. J. Market. 1994, 58, 20-38. [CrossRef]

52. Jarvenpaa, S.J.; Cantu, C.; Lim, S.Y. Trust in Virtual Online Environments. In The Wiley Blackwell Handbook of the Psychology of the Internet at Work; Wiley-Blackwell: Chichester, UK, 2017; pp. 103-130.

53. Burnham, T.A.; Frels, J.K.; Mahajan, V. Consumer Switching Costs: A Typology, Antecedents, and Consequences. J. Acad. Market. Sci. 2003, 31, 109-126. [CrossRef]

54. Kankanhalli, A.; Tan, B.C.Y.; Wei, K.K. Contributing Knowledge to Electronic Knowledge Repositories: An Empirical Investigation. MIS Quart. 2005, 29, 113-143. [CrossRef]

55. Blohm, I.; Zogaj, S.; Bretschneider, U.; Leimeister, J.M. How to Manage Crowdsourcing Platforms Effectively? Calif. Manag. Rev. 2018, 60, 122-149. [CrossRef]

56. Gdowska, K.; Viana, A.; Pedroso, J.P. Stochastic Last-mile Delivery with Crowdshipping. Transp. Res. Procedia 2018, 30, 90-100. [CrossRef]

57. Archetti, C.; Savelsbergh, M.; Speranza, M.G. The Vehicle Routing Problem with Occasional Drivers. Eur. J. Oper. Res. 2016, 254, 472-480. [CrossRef]

58. Jarvenpaa, S.L.; Knoll, K.; Leidner, D.E. Is anybody out There? Antecedents of Trust in Global Virtual Teams. J. Manag. Inform. Syst. 1998, 14, 29-64. [CrossRef]

59. Summers, R.; Wang, S.; Abd-El-Khalick, F.; Said, Z. Comparing Likert Scale Functionality Across Culturally and Linguistically Diverse Groups in Science Education Research: An Illustration Using Qatari Students' Responses to an Attitude Toward Science Survey. Int. J. Sci. Math. Educ. 2019, 17, 885-903. [CrossRef]

60. Huasheng News. One of the Series of Reports on the 10th Anniversary of the Approval of changsha-Zhuzhou-Xiangtan Two-type Social Experimental Zone: Green Practice on National Mission. Available online: http://hunan.voc.com.cn/article/201712/201712140811021643.html (accessed on 17 October 2019).

61. Wong, K.K.K. Partial Least Squares Structural Equation Modeling (PLS-SEM) Techniques Using SmartPLS. Market. Bull. 2013, 24, 1-32.

62. Gefen, D.; Rigdon, E.E.; Straub, D. Editor's Comments: An Update and Extension to SEM Guidelines for Administrative and Social Science Research. MIS Quart. 2011, 35, iii-xiv. [CrossRef]

63. Sebastian, K.; Adnan, U.H.; Eugene, K. Strategic SCM's Mediating Effect on the Sustainable Operations: Multinational Perspective. Organizacija 2019, 52, 219-235. 
64. Nania, R.M.; Sulung, L.A.K. The Management of Reputation and Activeness of Crowdfunding Players in Emerging Market Countries. J. Manag. Stud. 2019, 19, 298-308.

65. Nitzl, C.; Roldan, J.L.; Cepeda, G. Mediation Analysis in Partial Least Squares Path Modeling: Helping Researchers Discuss More Sophisticated Models. Ind. Manag. Data. Syst. 2016, 116, 1849-1864. [CrossRef]

66. Sharma, R.; Yetton, P.; Crawford, J. Estimating the Effect of Common Method Variance: The Method-Method Pair Technique with an Illustration from TAM Research. MIS Quart. 2009, 33, 473-490. [CrossRef]

67. Podsakoff, P.M.; Mackenzie, S.B.; Lee, J.Y.; Podsakoff, N.P. Common Method Biases in Behavioral Research: A Critical Review of the Literature and Recommended Remedies. J. Appl. Psychol. 2003, 88, 879-903. [CrossRef] [PubMed]

68. Chen, C.; Pan, S.; Wang, Z.; Zhong, R.Y. Using Taxis to Collect Citywide E-commerce Reverse Flows: A Crowdsourcing Solution. Int. J. Prod. Res. 2016, 55, 1-12. [CrossRef]

69. Guerlain, C.; Renault, S.; Ferrero, F. Understanding Construction Logistics in Urban Areas and Lowering Its Environmental Impact: A Focus on Construction Consolidation Centres. Sustainability 2019, 11, 6118. [CrossRef]

70. Kiba-Janiak, M.; Witkowski, J. Sustainable Urban Mobility Plans: How Do They Work? Sustainability 2019, 11, 4605. [CrossRef]

71. Keyju, L.; Junjae, C.; Jinwoo, K. A Courier Service with Electric Bicycles in an Urban Area: The Case in Seoul. Sustainability 2019, 11, 1225. [CrossRef]

(C) 2020 by the authors. Licensee MDPI, Basel, Switzerland. This article is an open access article distributed under the terms and conditions of the Creative Commons Attribution (CC BY) license (http://creativecommons.org/licenses/by/4.0/). 